\title{
Evolução antropométrica, postural e do equilíbrio de crianças com sobrepeso e obesidade
}

\section{Progression of anthropometric variables, posture and balance of obese and overweight children}

\author{
Carla Súnega Camargol; Karina Pereira² \\ ${ }^{1}$ Fisioterapeuta - UFTM, Departamento de Fisioterapia/ Instituto de Ciências da Saúde, e especialização em andamento de \\ Intervenção em Neuropediatria - UFSCar. São Carlos, SP - Brasil. \\ ${ }^{2}$ Professora Adjunta II - curso de Fisioterapia e do Programa de Pós-Graduação em Educação Física - UFTM - Instituto de Ciências da \\ Saúde. Uberaba, MG - Brasil.

\section{Endereço para correspondência} \\ Carla Súnega Camargo \\ Alameda Dom João VI, 14. Bairro Mercês \\ 38060-260 - Uberaba, MG - Brasil. \\ cacasunega@gmail.com
}

\section{Resumo}

Objetivo: Verificar dados antropométricos, a postura e o equilíbrio de crianças no Ambulatório de Distúrbios Nutricionais. Métodos: Participaram 20 crianças com idade de $8,4( \pm 1,5)$ anos, atendidas por uma equipe multiprofissional (médico, nutricionista e fisioterapeuta). Foram avaliados os dados antropométricos (IMC), a postura e o equilíbrio estático e dinâmico das crianças ao entrarem no projeto do ambulatório, e após três meses. Na primeira avaliação, passaram-se orientações quanto à dieta, à prática de exercício físico e à correção de postura. Os dados foram analisados de forma descritiva e pelo teste de Wilcoxon, nível de significância de 5\%. Resultados: Na primeira avaliação, as crianças apresentaram IMC de 23,67 ( $(2,6) \mathrm{kg} / \mathrm{m}^{2}$; e na segunda, de $23,65( \pm 2,4) \mathrm{kg} / \mathrm{m}^{2}$; a alteração postural mais observada foi abdômen protuso em ambas as avaliações $(75 \%$ e $70 \%$, respectivamente). No equilíbrio estático, houve diferença nas tarefas de imobilidade ( $\mathrm{p}=0,054$, do perfil eupráxico para hiperpráxico) e de apoio retilíneo ( $\mathrm{p}=0,021$, do dispráxico para eupráxico). Conclusão: $\mathbf{O}$ sobrepeso e a obesidade alteraram a postura e o equilíbrio das crianças avaliadas, e com as orientações foi possível verificar algumas mudanças no perfil psicomotor.

Descritores: Criança; Equilíbrio postural; Fisioterapia; Obesidade; Postura.

\begin{abstract}
Objective: To determine anthropometric data, posture and balance of children in the Nutritional Disorders Clinic. Methods: Twenty children aged $8.4( \pm 1.5)$ years were attended by a multidisciplinary team (physician, dietician and physiotherapist). We evaluated anthropometric data (BMI), posture, and static and dynamic balance of children on rolling in clinic's project and after three months. In the first evaluation, guidance was given on diet, physical exercise and correct posture. The data were analyzed descriptively and by means Wilcoxon test, with significance level of 5\%. Results: In the first evaluation, the children had a BMI of $23.67( \pm 2.6) \mathrm{kg} / \mathrm{m}^{2}$, and in the second, $23.65( \pm 2.4) \mathrm{kg} / \mathrm{m}^{2}$; postural change was observed protruding abdomen in both assessments $(75 \%$ and $70 \%$ respectively). In static equilibrium, there were differences in the immobility ( $p=0.054$, from eupraxic to hyperpraxic) and rectilinear support ( $\mathrm{p}=0.021$, from dyspraxic to eupraxic profile) tasks. Conclusion: Overweight and obesity altered posture and balance of the children, but with the guidance we observed some changes in psychomotor profile.
\end{abstract}

Key words: Child; Obesity; Physical therapy specialty; Postural balance; Posture. 


\section{Introdução}

Ao longo da vida, ocorre uma série de mudanças nas características antropométricas, estruturais e na composição corporal do ser humano. Essas características estão relacionadas de forma direta ao desenvolvimento motor e são influenciadas por experiências vivenciadas individualmente, direcionadas pela especificidade e complexidade das atividades ${ }^{1}$.

A obesidade, segundo as Diretrizes de Obesidade $(2009 / 2010)^{2}$, pode ser definida como o acúmulo de tecido gorduroso localizado ou generalizado, provocado por um desequilíbrio nutricional associado ou não a distúrbios genéticos ou endocrinometabólicos. O sobrepeso está relacionado com aumento de massa corporal em adultos e crianças. Na população infantil, ele é determinado quando a massa corporal está um pouco acima do adequado para a idade e a estatura da criança. Em casos de ganho de massa corporal contínua, progressiva e recorrente, há tendência a excesso de acúmulo de gordura, podendo gerar obesidade mórbida e outras síndromes metabólicas ${ }^{3}$.

O número de adipócitos é estabelecido na infância; portanto, é importante ressaltar que a diminuição de massa corporal ocorre pela perda de conteúdo lipídico celular, e não por diminuição do número de células ${ }^{4,5}$. A combinação de uma série de fatores durante a infância, tais como hábitos alimentares, estilo de vida, condições psicossocioeconômicas, genética, influenciam direta ou indiretamente no consumo e no gasto energético da criança ${ }^{6}$, podendo gerar acúmulo de gordura e, consequentemente, obesidade infantil.

O índice de massa corpórea (IMC) tem sido validado e utilizado em vários estudos como indicador de adiposidade em crianças ${ }^{7,8,9,10}$. É calculado em quilos, dividido pela estatura em metros ao quadrado ${ }^{11}$. Pode ser utilizado a partir dos seis anos de idade até a fase adulta, sendo classificado de acordo com a curva do percentil, levando em consideração as variáveis sexo e idade. As curvas do percentil composta no gráfico padronizado pela World Health Organization (WHO) ${ }^{12}$, em 1995, determina o tipo físico da criança pelos os valores de magreza corporal, menores ou iguais ao percentil 5; os eutróficos, entre 5 e 85 percentil; o sobrepeso, com ponto de corte 85; e a obesidade, acima de 95. Esses valores estão diretamente relacionados com o IMC e o sexo de cada criança.

Outro ponto a ser considerado é a boa postura, para isso o sistema musculoesquelético deve estar em equilíbrio, protegendo as estruturas de suporte contra lesões e deformidades, nas diferentes posições adotadas durante as atividades e o repouso. A má postura é uma relação menos eficiente desse equilíbrio, produzindo maior tensão sobre as estruturas e a base de suporte $^{13}$. As causas dessas alterações são inúmeras, e o excesso de massa corporal é uma delas, levando a diversas consequências a curto e em longo prazo, principalmente nas crianças. É na infância que o sistema musculoesquelético esta em desenvolvimento, tornando-se mais susceptível a deformidades pelo excesso de gordura corporal, diminuição da estabilidade e aumento das necessidades de adaptação do corpo ${ }^{14}$.

A avaliação do alinhamento postural estático é realizada ao analisar o posicionamento das várias articulações e segmentos corporais em relação à posição anatômica ${ }^{13}$.

No obeso, há uma concentração de gordura na região abdominal, deslocando o centro de gravidade do corpo para frente, acarretando em aumento da lordose e anteversão pélvica; além da acentuação na cifose torácica, do aumento da lordose cervical e da protrusão de cabeça. Esse quadro evolui, ocasionando encurtamentos e alongamentos de diversas estruturas de suporte, acarretando maior inclinação anterior da pelve e provocando a rotação interna de quadris, coxas, joelhos, tornozelos e pés, surgindo o valgismo de joelho e o aplainamento dos pés ${ }^{15,16}$. As alterações posturais mais encontradas em crianças obesas são: hiperlordose lombar, joelhos valgos ou hiperestendidos e pés planos, bem como dores na coluna lombar e nos joelhos ${ }^{17}$, tornando os indivíduos obesos mais suscetíveis a lesões devido à sobrecarga nos segmentos corporais ${ }^{18}$. 
A prática de exercício físico pode contribuir para a redução do peso corporal. Observase que há uma relação inversa entre a atividade física e o índice de gordura corporal, uma vez que não praticar exercícios físicos aumenta os riscos de a pessoa tornar-se obesa, e a obesidade, por sua vez, pode acarretar diminuição da prática de tal atividade ${ }^{19}$. Assim, o desempenho físico prejudicado em crianças obesas pode ser justificado pela diminuição da atividade motora e pela falta de interesse em praticar esportes. Segundo Brum e Rosa Neto ${ }^{16}$, essas crianças possuem níveis de habilidades físicas comprometidos, por apresentarem redução da capacidade cardiorrespiratória, maior gasto energético na prática de atividades e menor desempenho físico, comparadas as possuem massa corporal considerada normal para a idade ${ }^{10}$.

A maior parte dos trabalhos encontrados na literatura traça o perfil de crianças com obesidade em diferentes aspectos, sendo escassas as pesquisas quanto à atuação de uma equipe multiprofissional na prevenção e no atendimento ambulatorial fisioterapêutico dessa população.

Diante do exposto, neste estudo, visa-se mostrar a evolução do perfil antropométrico, da postura e do equilíbrio de crianças com sobrepeso e obesidade, assistidas por uma equipe multiprofissional composta por fisioterapeuta, médico e nutricionista, em um período de três meses.

\section{Método}

O estudo foi aprovado pelo comitê de Ética em Pesquisa da Universidade Federal do Triângulo Mineiro, sob o protocolo número 1.492/2009, sendo realizado no Ambulatório de Pediatria do Hospital de Clínicas da Universidade Federal do Triângulo Mineiro, Uberaba (MG), no período de janeiro a outubro de 2011, seguindo as normas para pesquisas com seres humanos, de acordo com a Resolução CNS 196 de 10 de outubro de 1996 do Conselho Nacional de Saúde.
Foram avaliadas 94 crianças, dessas apenas 20 foram selecionadas, pois se enquadraram nos critérios de inclusão da pesquisa, segundo os quais a criança deveria estar na faixa etária entre seis e dez anos de idade; apresentar dados antropométricos de no mínimo 85 e acima de 95 percentil; não ter patologias cardiopulmonares, neurológicas e musculoesqueléticas associadas que impedissem e/ou prejudicassem a execução da avaliação física; ter aceitação da família por meio da assinatura do Termo de Consentimento Livre e Esclarecido para ser submetida à exame físico; ter capacidade de permanecer na postura ortostática sem apoio, compreender as orientações durante a coleta dos dados; comparecer na reavaliação após três meses; ser atendida e acompanhada pela equipe multiprofissional composta por profissionais e acadêmicos de cada um dos cursos de fisioterapia, medicina, nutrição. Os critérios de exclusão foram: utilizar medicamentos para emagrecimento, apresentar contraindicação para atividade física e não aderir às orientações propostas.

A avaliação total da criança durou em torno de uma hora, sendo primeiramente avaliada pela médica pediatra, que solicitava os exames laboratoriais necessários. Em seguida, a nutricionista realizava a avaliação nutricional e coletava os dados antropométricos. A estatura $(\mathrm{cm})$ foi verificada por meio de uma haste de metal inflexível, marcada em centímetros $(\mathrm{cm})$ até a altura de dois metros, o peso $(\mathrm{kg})$ foi obtido por meio da balança mecânica analógica, e o cálculo do índice de massa corpórea (IMC), mediante o cálculo do peso $(\mathrm{kg})$ dividido pela estatura $\left(\mathrm{m}^{2}\right)$. O percentil foi identificado na curva pelo IMC, idade e sexo da criança.

Na avaliação fisioterapêutica, inicialmente foram coletados os dados pessoais do participante; em seguida, foi realizada a avaliação da postura, estando a criança na posição ortostática, descalça, pés paralelos e unidos, os braços ao longo do corpo nos seguintes planos: sagital (anteroposterior), frontal (lateral ou coronal) e transversal (horizontal) ${ }^{13}$. Dois avaliadores trei- 
nados observavam e anotavam as alterações posturais detectadas em uma tabela elaborada com os desvios posturais mais frequentes em crianças obesas, hiperlordose lombar, anteversão pélvica, acentuação da cifose torácica, aumento da lordose cervical, anteriorização da cabeça, protrusão de ombros, joelhos valgos, joelhos hiperestendidos e abdômen protuso (descrita por Brandalize e Leite $)^{17}$. Por último, foi avaliado o perfil psicomotor, segundo a Bateria Psicomotora, nas tarefas de equilíbrio estático e dinâmico (conforme Fonseca ${ }^{20}$ ). Na avaliação do equilíbrio, as instruções foram transmitidas verbalmente à criança, sendo esse fator dividido em três subfatores, a saber: imobilidade, equilíbrio estático e dinâmico, detalhados a na sequência.

A imobilidade é a capacidade de inibir voluntariamente todo e qualquer movimento durante um determinado momento. Assim, considerando esse fator a criança deve manter-se na posição ortostática por 60 segundos, com pés juntos e paralelos, olhos fechados e braços ao longo do corpo.

O equilíbrio estático é realizado por meio de três tarefas, apoio retilíneo, equilíbrio na ponta dos pés e apoio unipodal, com duração de 20 segundos, efetuadas em duas tentativas, na qual, as crianças devem manter os olhos fechados e as mãos apoiadas na cintura. No apoio retilíneo, a criança coloca um pé na frente do outro de forma que estabeleça o contato do calcanhar de um pé com a ponta do pé contrário; no equilíbrio na ponta dos pés, ela deve estar com os pés juntos e manter-se sobre seu terço anterior; e no apoio unipodal, a criança apoia-se em um único pé, a perna contrária deve estar com o joelho fletido a $90^{\circ}$ graus.

O equilíbrio dinâmico exige uma orientação controlada do corpo em movimento no espaço, com as mãos na cintura, sobre uma linha de três metros de comprimento. As tarefas são divididas em quatro subfatores: marcha controlada, evolução na trave, saltos com apoio unipodal e com pés juntos, porém não foi avaliado o segundo subfator (evolução na trave) devido ao curto tempo de atendimento. Na marcha controlada, a criança deve percorrer a trajetória de modo que o calcanhar de um dos pés toque a ponta do outro sucessivamente. Nos saltos com apoio unipodal, a criança deve escolher o pé no qual realizará a tarefa de forma espontânea e percorrer os três metros pré-definidos. O último subfator é dividido em três tarefas: para frente, para trás e com os olhos fechados, realizando os saltos com os pés paralelos e unidos.

Em cada tarefa, a criança pode ser classificada em quatro perfis psicomotores, sendo eles:

- 1 ponto = perfil apráxico: realização incompleta, inadequada e imperfeita da tarefa;

- 2 pontos = perfil dispráxico: realização da tarefa com dificuldades de controle;

- 3 pontos = perfil eupráxico: realização completa, adequada e controlada da tarefa;

- 4 pontos = perfil hiperpráxico: realização perfeita, precisa, melódica e com facilidade de controle.

Cada criança foi avaliada em dois momentos. A avaliação inicial foi realizada quando a criança iniciava o projeto no Ambulatório de Distúrbios Nutricionais; e final, após três meses do início do projeto. Após a avaliação inicial, os responsáveis e as crianças recebiam orientações sobre como melhorar a postura nas atividades de vida diária - que deveriam ser seguidas ao longo de três meses - e informações quanto à importância da prática regular de atividades físicas, além das oferecidas pela escola.

Os dados foram analisados de forma descritiva simples, média, desvio-padrão e porcentagem. As variáveis quantitativas equilíbrio estático e dinâmico foram analisadas por meio do programa GraphPad InStat, sendo inicialmente submetidas ao teste Wilcoxon para verificar o efeito das orientações e desempenhos das crianças na primeira avaliação com relação à segunda, quanto ao IMC e ao equilíbrio estático e dinâmico. Foi considerado um nível de significância de $\mathrm{p} \leq 0,05$. 


\section{Resultados}

Entre as 20 crianças avaliadas, 11 são meninas; e 9, meninos, com média de idade de 8,4 $( \pm 1,5)$ anos. Na primeira avaliação, $15 \%$ foram consideradas com sobrepeso; e $85 \%$, com obesidade, apresentando como IMC médio 23,67 $( \pm 2,6) \mathrm{kg} / \mathrm{m}^{2}$. Na reavaliação, todas as crianças foram consideradas obesas, com IMC médio de $23,65( \pm 2,4) \mathrm{kg} / \mathrm{m}^{2}$. Não foi observada diferença significativa no IMC dos participantes entre as avaliações $(\mathrm{p}=0,270)$.

$\mathrm{Na}$ primeira avaliação, pode-se observar na Tabela 1 que a maioria das crianças apresentou abdômen protuso, anteversão pélvica, hiperextensão de joelho e protrusão de ombros. $\mathrm{Na}$ segunda, verificaram-se aumento do número de crianças com abdômen protuso - predominante em ambas as avaliações -, hiperextensão de joelhos, hiperlordose e protusão de ombros.

Tabela l: Alterações posturais observadas nas crianças na primeira e na segunda avaliação

\begin{tabular}{ccc}
\hline $\begin{array}{c}\text { Alterações } \\
\text { posturais }\end{array}$ & $\begin{array}{c}\text { Avaliação } \\
\text { inicial (\%) }\end{array}$ & $\begin{array}{c}\text { Avaliação } \\
\text { final (\%) }\end{array}$ \\
\hline Hiperlordose & 50 & 55 \\
Hipercifose torácica & 10 & 25 \\
Hiperlordose cervical & 20 & 5 \\
Anteversão pélvica & 65 & 30 \\
Protusão de ombros & 60 & 50 \\
Hiperextensão de & 65 & 70 \\
joelhos & 40 & 10 \\
Joelhos valgos & 75 & 70 \\
Abdômen protuso & & \\
\hline
\end{tabular}

A Figura 1 mostra a média do perfil psicomotor das quatro atividades obtidas pelas crianças nas tarefas do equilíbrio estático durante a primeira e a segunda avaliação.

No desempenho motor dos participantes no estudo nos testes de equilíbrio estático, houve diferença significativa de perfil psicomotor na tarefa de mobilidade ( 3 e 4 , primeira e segunda avaliação, respectivamente; $\mathrm{p}=0,054)$ e de apoio retilíneo ( 2 e 3, nessa ordem; $\mathrm{p}=0,021$ ).
A Figura 2 mostra a média do perfil psicomotor das três atividades obtidas pelas crianças nas tarefas do equilíbrio dinâmico, durante a primeira e a segunda avaliação. Nos testes de equilíbrio dinâmico não houve diferenças significativas estatisticamente.

De acordo com o questionário de identificação de hábitos, na avaliação inicial, 25\% das crianças relataram realizar atividade física além das oferecidas na escola; após as orientações quanto à importância da prática de exercícios físicos, 25\% iniciaram atividades extraescola, 10\% pararam e $20 \%$ deram continuidade à prática da atividade extraescolar.

\section{Discussão}

Após três meses, os valores de IMC das crianças com obesidade não apresentaram diferenças significativas em relação à avaliação inicial, entretanto, no estudo de Berleze ${ }^{10}$, o intervalo de sete meses entre a pré- e pós-intervenção $\left(20,094,30 \mathrm{~kg} / \mathrm{m}^{2}\right.$ e $\left.19,013,78 \mathrm{~kg} / \mathrm{m}^{2}\right)$ permitiu observar mudanças significativas nos valores de IMC. Dessa forma, o período de três meses pode ter sido insuficiente para observar mudanças neste estudo.

Em relação à avaliação postural, na primeira avaliação foi observado que a maioria das crianças apresentou abdômen protuso, anteversão pélvica, hiperextensão de joelho e, protusão de ombros. Na segunda, houve diminuição do número de participantes com abdômen protuso e protusão de ombros, e um aumento do número de crianças com hiperextensão de joelhos e hiperlordose lombar. Sugerindo que as orientações não foram seguidas corretamente e o intervalo entre as avaliações foi escasso para se observar melhora do quadro. Algumas dessas alterações estão de acordo com o estudo de Arruda e Simões ${ }^{21}$, no qual verificaram grande porcentagem de crianças com abdômen protuso, hiperlordose, anteversão pélvica, além de apresentarem escoliose e pés planos. Cicca, João Amado e $\mathrm{Sacoo}^{22}$ sugerem que os joelhos valgos, 


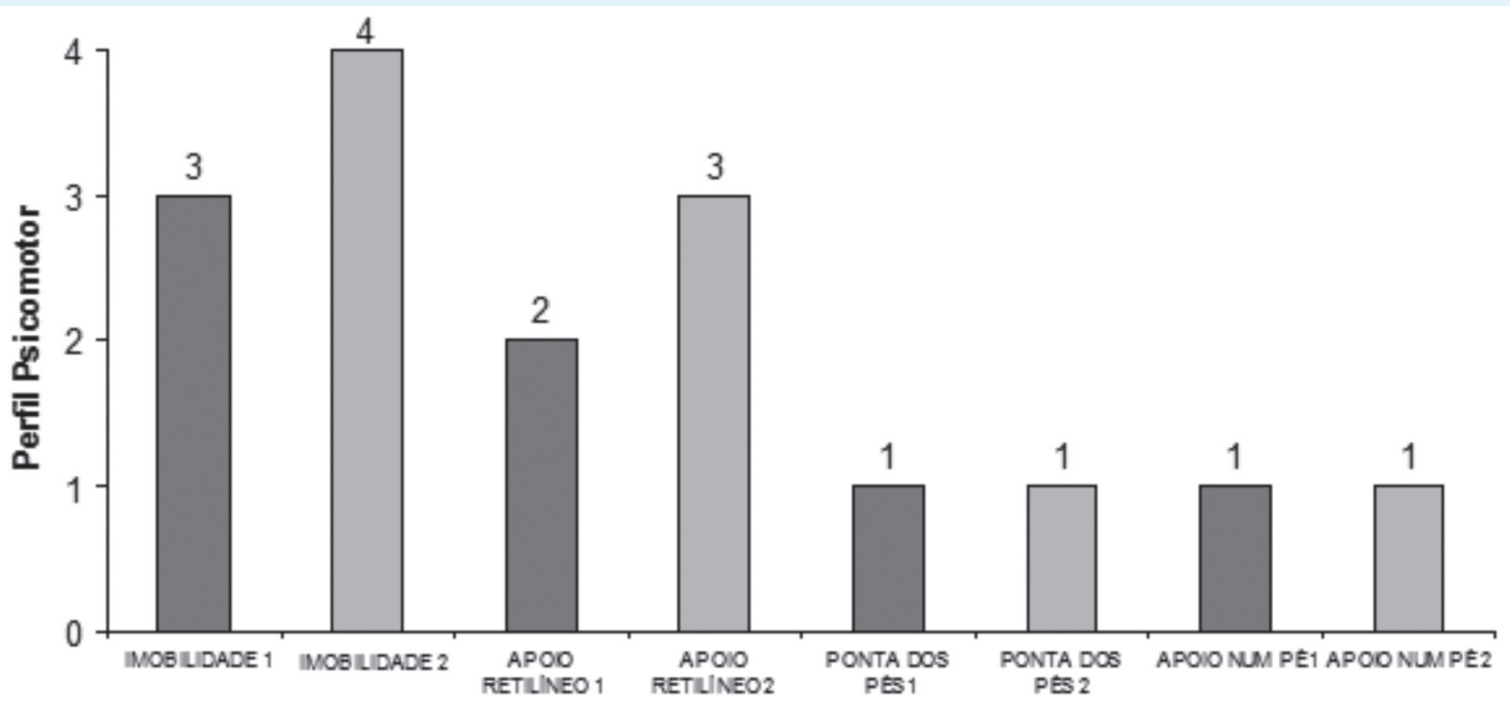

Equilibrio Estatico

Figura l: Média do perfil psicomotor das tarefas do fator equilíbrio estático. 1 - perfil apróxico; 2 - perfil dispróxico; 3 - perfil eupróxico; 4 - perfil hiperpróxico

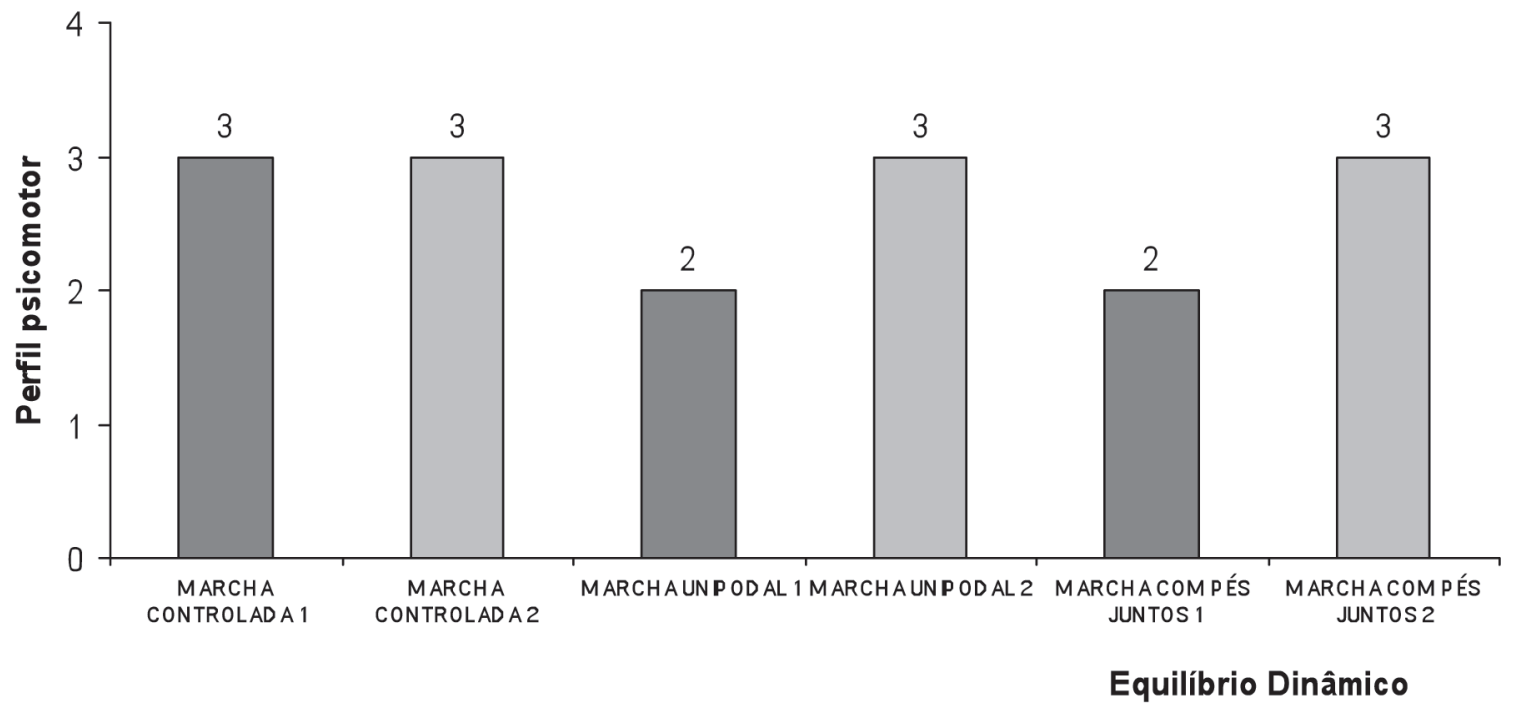

Figura 2: Média do perfil psicomotor das tarefas do fator equilíbrio dinâmico. 1 - perfil apróxico; 2 - perfil dispróxico; 3 - perfil eupróxico; 4 -perfil hiperpróxico

em crianças acima dos 7 anos de idade é consequência de compensações posturais, devido à massa corporal acima do considerado normal para a idade, tendo como resultado o valgismo de tornozelo e pé plano.

$\mathrm{O}$ artigo de Calvete $\mathrm{C}^{18}$ mostra que em diferentes estudos há grande incidência de crianças obesas com abdômen protuso e tranferência do centro de gravidade corporal para frente, geran- do hiperlordose lombar e anteversão de quadril, que são compensadas com uma cifose dorsal acentuada, protusão de cabeça, valgismo de joelho e o aplainamento dos pés.

De acordo com Kussuki, João e Cunha ${ }^{14}$, as características posturais marcantes entre os sete e dez anos são hiperlordose lombar, hipercifose torácica e protrusão da cabeça, sendo essas em maior incidência em crianças obesas. A postura, 
por ser um equilíbrio neuromotor, é resultante de reflexos sensitivos, integrados ao sistema nervoso, sendo influenciada pela cultura, hereditariedade, personalidade, sentimentos e emoções.

Quanto ao equilíbrio, foi observado que o perfil psicomotor das crianças ao longo dos três meses apresentou melhora no desempenho motor, principalmente nas tarefas de imobilidade e apoio retilíneo, evoluindo do perfil eupráxico para hiperpráxico e do dispráxico para eupráxico, respectivamente. Nas tarefas do equilíbrio dinâmico, não houve melhora significativa no desempenho psicomotor das crianças. O estudo aqui apresentado corrobora os trabalhos encontrados na literatura atual ${ }^{1,16,23}$ em que o perfil psicomotor de crianças é inversamente proporcional ao excesso de peso, pois crianças obesas demonstraram dificuldade na realização de algumas tarefas como sustentar-se sobre o ante pé e sobre um dos pés, por 20 segundos, com os olhos fechados.

Lemos, David, Teixeira e Mota $^{23}$ em sua revisão bibliográfica sobre o equilíbrio corporal em crianças obesas afirmam que, para a obtenção do equilíbrio, é necessária a contribuição dos fatores antropométricos e biomecânicos, exigindo uma complexa interação do sistema sensório-motor, que atua juntamente com as vias aferentes sensoriais, produzindo respostas de correção postural aos desvios do centro de gravidade do corpo. Dessa forma, a obesidade infantil, tem como consequência a alteração na postura corporal, influenciando diretamente no equilíbrio do corpo.

Além de verificar-se diferença entre as vivências corporais de crianças obesas e as de não obesas, observa-se também que a prática diária de atividade física proporciona melhor desempenho motor para a população infantil nessas duas condições. Berleze, Haeffner e Valentini ${ }^{25}$ também afirmam que a obesidade das crianças influencia de forma negativa no desempenho motor, pois ao comparar crianças eutróficas com as obesas, houve diferença no equilíbrio estáti$\mathrm{co}$, independentemente da classe social e do gênero dessas últimas.
O mesmo foi observado na pesquisa de Brum e Rosa $\mathrm{Neto}^{16}$, que evidenciaram por meio da Escala de Desenvolvimento Motor, que a idade motora obtida pelas crianças com obesidade na tarefa de equilíbrio foi "normal baixo". Os autores justificaram que as alterações posturais apresentadas pelas crianças podem acarretar atraso no desenvolvimento neuropsicomotor.

Estudos com adolescentes indicam que um programa de redução de massa corporal, utilizando somente a dieta, tem como resultado maior perda de massa muscular e menor perda de gordura, enquanto que um programa associado a exercícios físicos proporciona maior perda de gordura e menor perda de massa magra. Mencionam também que os exercícios aeróbicos tem como resultado melhora da composição corporal e cardiorrespiratória; e os anaeróbicos, manutenção e aumento de massa magra ${ }^{19,24}$.

Sabendo que há uma relação inversa entre a atividade física e o índice de gordura corpo$\mathrm{ral}^{19}$, pode-se sugerir que as orientações quanto à prática de atividades físicas fornecidas às crianças e seus cuidadores, permitiu observar melhoras em seu desempenho psicomotor. Além disso, o trabalho de diferentes profissionais em equipe $^{10}$, assistindo os múltiplos aspectos envolvidos na criança com obesidade, contribui para a melhora do seu bem-estar físico e emocional.

Destaca-se como limitações deste estudo o tamanho da amostra e a não inclusão de um grupo controle. Salienta-se também que houve dificuldade para discutir os dados do estudo, devido ao número insuficiente de trabalhos publicados na área e os poucos existentes apresentarem diferentes metodologias e faixas etárias, comprometendo a comparação entre os estudos.

\section{Conclusão}

Apesar da adesão as orientações quanto à atividade física e as mudanças na postura durante a realização das atividades de vida diária não terem sido monitorizadas com rigor, os dados encontrados evidenciaram que as crianças 
obtiveram mudança de hábitos, pois na avaliação final $49 \%$ estavam realizando exercício físico, enquanto na inicial apenas $25 \%$ o praticaram.

Com base nos resultados deste estudo, pode-se inferir que três meses de acompanhamento das crianças analisadas não foram suficientes para modificar o IMC $(23,67( \pm 2,6) \mathrm{kg} /$ $\mathrm{m}^{2}$, na primeira avaliação, e 23,65 $( \pm 2,4) \mathrm{kg} / \mathrm{m}^{2}$, na segunda), nem promover alterações posturais das obesas. No entanto, o item equilíbrio estático permitiu detectar mudanças no desempenho motor dos participantes deste trabalho, os quais apresentaram perfil hiperpráxico em imobilidade; e eupráxico, no apoio retilíneo, resultando em ótimo desempenho nessas tarefas propostas pela Bateria Psicomotora.

\section{Agradecimentos}

Os autores agradecem aos responsáveis pelas crianças que frequentam o Ambulatório de Distúrbios Nutricionais da Universidade Federal do Triângulo Mineiro, a equipe multidisciplinar do Projeto de Extensão "Avaliação postural e do equilíbrio de crianças e adolescentes com obesidade", e ao Programa Institucional de Bolsa de Extensão Universitária da Universidade Federal do Triângulo Mineiro (UFTM).

\section{Referências}

1. Ferreira M, Böhme MTS. Diferenças sexuais do desempenho motor de crianças: influência da adiposidade corporal. Rev Pau Educ Fís, São Paulo [periódico na internet]. 1998; 12(2):181-92 [acesso em 2011 fev 13]. Disponível em: <http://citrus.uspnet.usp. br/eef/uploads/arquivo/v12\%20n2\%20artigo7.pdf >.

2. Associação Brasileira para o Estudo da Obesidade e da Síndrome Metabólica. Diretrizes brasileiras de obesidade 2009/2010 [internet]. $3^{\text {a }}$ ed. Itapevi, SP: AC Farmacêutica; 2009 [acesso em 2011 fev 11]. Disponível em: <http://www.abeso.org.br/pdf/ diretrizes_brasileiras_obesidade_2009_2010_1.pdf $>$.
3. Coutinho W. Consenso latino-americano de obesidade. Arq Bras Endocrinol Metab 1999; 43(1): 21-67 [acesso em $2011 \mathrm{fev}$ 14]. Disponível em: <http:// www.scielo.br/pdf/abem/v43n1/12049.pdf >.

4. Giugliano R, Carneiro EC. Fatores associados à obesidade em escolares. J Pediatria, Rio de Janeiro [periódico na internet]. 2004;80(1):17-22 [acesso em 2011 jan 14]. Disponível em: <http://www.scielo.br/ pdf/jped/v80n1/v80n1a05.pdf $>$.

5. Soares LD, Petroski EL. Prevalência, fatores etiológicos e tratamento da obesidade infantil. Revista Brasileira de Cineantropometria e Desempenho Humano, Florianópolis [periódico na internet]. 2003;5(1):63-74 [acesso em 2011 jan 23]. Disponível em: <http://74.125.155.132/scholar?q=cache :KNjEIr1YV8gJ:scholar.google.com/+Preval\%C3\%AAnc ia,+ fatores+etiol $\%$ C3\%B3gicos+e+tratamento+da+obesi dade+infantil\&hl=pt-BR\&as_sdt=0\&as_vis=1> .

6. Francishi RPP, Pereira LO, Freitas CS, Klopfer M, Santos RC, Vieira P, et al. Obesidade: atualização sobre sua etiologia, morbidade e tratamento. Rev Nutrição, Campinas [periódico na internet]. 2000 jan/abr;13(1):17-28 [acesso em 2011 fev 14]. Disponível em: <http://www.scielo.br/scielo.php?script=sci_art text\&pid=S1415-52732000000100003>.

7. Giugliano R, Melo ALP. Diagnóstico de sobrepeso e obesidade em escolares: utilização do índice de massa corporal segundo padrão internacional. J Pediatr, Rio de Janeiro [periódico na internet]. 2004;80(2):129-34 [acesso em 2011 jan 28]. Disponível em: <http://www.scielo.br/pdf/\%0D/jped/v80n2/ v80n2a10.pdf $>$.

8. Lopes PCS, Prado SRLA, Colombo P. Fatores de risco associados à obesidade e sobrepeso em crianças em idade escolar. Rev Bras Enferm, São Paulo [periódico na internet]. 2010 jan/fev;63(1):738. Disponível em: <http://www.scielo.br/pdf/ reben/v63n1/v63n1a12.pdf $>$.

9. Rodrigues PPC. Estudo da relação entre o índice da massa corporal (IMC) e a postura corporal em estudantes do ensino fundamental da escola São Judas Tadeu, Tubarão/SC [monografia na internet]. Tubarão, SC: Universidade do Sul de Santa Catarina; 2007 [acesso em 2011 jan 15]. Disponível em: <http:// www.fisio-tb.unisul.br/Tccs/07b/priscila/TCC_ priscila.pdf $>$. 
10. Berleze, A. Efeitos de um programa de intervenção motora em crianças, obesas e não obesas, nos parâmetros motores, nutricionais e psicossociais. 2008. 71 f. [dissertação de doutorado em ciências do movimento humano na internet). Porto Alegre: Universidade Federal do Rio Grande do Sul; 2008 [acesso em 2011 fev 22]. Disponível em: <http:// www.bibliotecadigital.ufrgs.br/da.php?nrb=0006383 $33 \& l o c=2008 \& l=b 28 c 4 e 86 e b 652 c 15>$.

11. Bachiega CMMV. A prevalência de sobrepeso e obesidade em escolares e a influência nas alterações posturais do aparelho locomotor. 2006. 99 f. [dissertação de mestrado em Saúde Coletiva na internet]. Botucatu: Faculdade de Medicina de Botucatu, Universidade Estadual Paulista; 2006 [acesso em 2011 jan 28]. Disponível em: <http:// www.rebrae.com.br/artigo/prevalencia.pdf $>$.

12. World Health Organization. Obesity: World Health Organization. Physical status: The use and interpretation of anthropometry. Report of a WHO expert committee [internet]. Geneva. 1995 [acesso em 2011 jun 1]. Disponível em: <http://whqlibdoc.who. int/trs/WHO_TRS_854.pdf $>$.

13. Kendall FP, McCreary EK, Provance PE, Rodgers MM, Romani WA. Músculos: provas e funções. $5^{\mathrm{a}}$ ed. São Paulo: Manole; 2007.

14. Kussuki MOM, Amado João SMA, Cunha ACP. Caracterização postural da coluna de crianças obesas de 7 a 10 anos. Fisioter Mov, Curitiba [periódico na internet]. 2007 jan/mar;20(1):77-84 [acesso em 2011 fev 22]. Disponível em: <http://www2.pucpr.br/ reol/index.php/RFM?dd1=1516\&dd99=view $>$.

15. Bankoff ADP, Zamai CP, Schimdt A, Ciol P, Barros DD. Estudo das alterações morfológicas do sistema locomotor: postura corporal x obesidade. Rev Educ Fís, Maringá [periódico na internet]. 2003;14(2):418 [acesso em 2011 jan 28]. Disponível em: <http:// periodicos.uem.br/ojs/index.php/RevEducFis/ article/view/3468/2474>.

16. Brum KO, Rosa Neto F. O perfil motor de escolares obesos. Revista Digital, Buenos Aires [periódico na internet]. 2009;134(14) [acesso em $2011 \mathrm{fev}$ 20]. Disponível em: <http://www.efdeportes.com/ efd134/perfil-motor-de-escolares-obesos.htm>.

17. Brandalize M, Leite N. Alterações ortopédicas em crianças e adolescentes obesos. Fisioter Mov, Curitiba [periódico na internet]. 2010;23(2):2838 [acesso em $2011 \mathrm{fev}$ 17]. Disponível em: <http://www2.pucpr.br/reol/index.php/RFM/ view/?dd1=3599>.
18. Calvete SA. A relação entre alteração postural e lesões esportivas em crianças e adolescentes obesos. Motriz, Rio Claro [periódico na internet]. 2004 maio/ ago;10(2):67-72 [acesso em $2011 \mathrm{fev}$ 11]. Disponível em: <http://www.periodicos.rc.biblioteca.unesp.br/ index.php/motriz/article/viewArticle/602>.

19. Fernandez AC, Mello MT, Tufik S, Castro PM, Fisberg M. Influência do treinamento aeróbio e anaeróbio na massa de gordura corporal de adolescentes obesos. Rev Bras Med Esporte, Campo Grande [periódico na internet]. 2004;19(3):152-8 [acesso em 2011 mar 20]. Disponível em: <http:// www.scielo.br/pdf/\%0D/rbme/v10n3/21143.pdf >.

20. Fonseca V. Manual de Observação Psicomotora, significação psiconeurológica dos fatores psicomotores. Porto Alegre: Artes Médicas; 1995.

21. Arruda MF, Simões MJS. Perfil do excesso de peso na infância e sua influência sobre o sistema musculoesquelético de escolares. Cinergis, Araraquara [periódico na internet]. 2007 jul/ dez;8(2):37-47 [acesso em 2011 mar 20]. Disponível em: <http://www.sumarios.org/sites/default/files/ pdfs/64497_7268.pdf>.

22. Cicca LO, João SMA, Sacco ICN. Caracterização postural dos membros inferiores de crianças obesas de 7-10 anos. Fisioter Pesqui, São Paulo [periódico na internet]. 2007;14(2):40-6 [acesso em 2011 mar 20]. Disponível em: <http://www.fm.usp.br/gdc/docs/ fofito_26_mai\%20-\%20ago\%202007.pdf\#page=42>.

23. Lemos LFC, David AC, Teixeira CS, Mota CB. Obesidade infantil e suas relações com o equilíbrio corporal. Acta Fisiatr, Brasília. 2009;6(3):138-419.

24. Sabia RV, Santos JE, Ribeiro RPP. Efeito da atividade física associada à orientação alimentar em adolescentes obesos: comparação entre o exercício aeróbio e anaeróbio. Rev Bras Med Esporte, Ivaiporã [periódico na internet]. 2004;10(5):49-55 [acesso em 2011 mar 20]. Disponível em: <http://www.scielo.br/ pdf/rbme/v10n5/v10n5a02.pdf >. 